\title{
Kırılgan Beşlide Tasarruf-Yatırım Açığının Ekonomik Büyümeye Etkileri: Yeni Nesil Bir Ekonometrik Analiz
}

\author{
The Effects of Saving-Investment Gap on Economic Growth in the Fragile Five: A New \\ Generation Econometric Analysis
}

İsmet GÖÇER', Tuğba AKIN²

\begin{abstract}
ÖZET
$\mathrm{Bu}$ çalışmada; Hindistan, Brezilya, Endonezya, Türkiye ve Güney Afrika'da tasarruf- yatırım açığı ile ekonomik büyüme arasındaki ilişki, yeni nesil zaman serisi yöntemleriyle analiz edilmiştir. Çalışma sonucunda; tasarruf-yatırım açığının, ülkelerin ekonomik büyümeleri negatif etkilediği bulgusuna ulaşılmıştır. Modellerin hata düzeltme mekanizmaları çalışmaktadır.
\end{abstract}

Anahtar Kelimeler: Tasarruf-Yatırım Açığı, Ekonomik Büyüme, Kırılgan Beşli.

\section{Gíriş}

Az gelişmiş ve gelişmekte olan ülkelerin ortak sorunu; kişi başına düşen gelirlerinin düşük olması ve buna bağlı olarak ulusal tasarruflarının, yatırımlarını finanse edememesi, yani tasarruf-yatırım açığı yaşamaları nedeniyle tüketim ve yatırım harcamaları için yurtdışı sermaye girişlerine intiyaç duymalarıdır (Yeldan, 2009). Söz konusu ülkelerin makroekonomik göstergelerindeki istikrarsızlıklar nedeniyle, bu ülkelere yönelik sermaye girişleri çoğunlukla kısa vadeli olmakta ve ülkelerin, istikrarlı bir ekonomik büyümeye sahip olmalarına yetmemektedir (Kaya vd., 2009). Kısa vadeli sermaye girişleri ile yatırımlarını finanse etmeye çalışan ülkeler, sermaye girişlerini arttırabilmek amacıyla genellikle faiz oranlarını, dünya faiz oranlarının üstünde tutmakta ve bu sayede büyümelerini arttırmaya çabalamaktadırlar (Prasad vd., 2007). Ancak bu kez de yerli firmaların yatırım maliyetleri artmakta ve ülkeler bu kanaldan zarar görmektedir. Diğer yandan yurtiçi tasarruflar, yatırımları finanse etmeye yetmediğinde, yatırımlar için sürekli dış borç almak zorunda kalınmakta, bu da ülkenin dış borç stokunu arttırarak, cari işlemler açığına da neden olmaktadır. Bu durumda ülkeler döviz kuru şoklarına ve dış ekonomik şoklara karşı daha kırılgan bir hale gelmektedir (Insel ve Sungur, 2003; Örnek, 2008, Gente vd. 2014).

\begin{abstract}
In this study, the relationship between savinginvestment gap and economic growth in India, Brazil, Indonesia, Turkey and South Africa was analyzed via a new generation time series analysis method. In conclusion; it was found that savinginvestment deficit of countries affects their economic growth negatively. Error correction mechanisms of models are working.
\end{abstract}

Keywords: Saving-Investment Gap, Economic Growth, Fragile Five.

ABD Merkez Bankası Fed'in 2002-2004 döneminde uygulamış olduğu parasal genişleme politikası kapsamında faiz oranları \%1'e kadar düşmüş, dünyada bir dolar bolluğu dönemi yaşanmıştır. Bu dönemde Brezilya, Endonezya ve Güney Afrika gibi gelişmekte olan ülkelere yönelik kısa vadeli sermaye hareketleri hızlanmış ve bu ülkeler, sermaye kontrollünü büyük ölçüde kaybetmiş (Ahmed ve Zlate, 2014), bu ülkelerde ekonomik faaliyetlerin dış sermaye girişine bağımlılığı artmıştır (Gallagher, 2012). 2008 küresel ekonomik krizinden çıkış sürecinde de Fed benzer bir genişletici para politikası uygulamaya başlamış, \%5'in üzerinde olan faiz oranını kademeli olarak $\% 0.25$ 'e kadar indirmiş ancak, hedeflenen ekonomik göstergeleri takiben, parasal sıkılaştırmaya gideceğini açıklamıştır. Tasarruf-yatırım açı̆̆ yaşayan ve bunu da büyük ölçüde kısa vadeli sermaye girişleri ile finanse etmeye çalışan ülkeler, Fed'in Mayıs 2013'te tahvil alımlarını azaltarak ve zaman içinde faiz oranlarını artırarak sıkılaştırıcı para politikası izleyeceğini açıklamasıyla birlikte, dış finansman konusunda sıkıntılı bir döneme girmiştir. Bu süreçte gelişmekte olan ülkelerin Menkul Kıymetler Borsaları düşüşe geçmiş, ulusal paraları değer kaybetmiştir (Aizenman vd. 2014).

ABD'li bir yatırım bankası olan Morgan Stanley tarafından Ağustos 2013'te yayınlanan ekonomi 
raporunda; ülkelerin cari açı/GSYH oranları değerlendirilerek, sermaye girişlerine karşı en hassas görülen ülkeler irdelenmiş ve Hindistan, Brezilya, Endonezya, Türkiye ve Güney Afrika "kırılgan beşli" olarak adlandırılmış, Türkiye ise bu sepetteki en kırılgan ülke ilan edilmiştir. Söz konusu rapora göre bahsi geçen ülkelerin temel ekonomik sorunları; ulusal tasarruflarının, yatırımlarını finanse etmeye yetmemesi nedeniyle önemli ölçüde cari işlemler açığı vermeleri, zayıf ekonomik büyüme, enflasyon riski, ekonomik büyümelerinin büyük ölçüde yabancı sermayeye bağımlı olması ve buna bağlı olarak ortaya çıkan kur riskidir (Morgan Stanley, 2013). Bu durum, söz konusu ülkeleri dış şoklara karşı daha savunmasız hale getirmekte ve sürdürülebilir yüksek bir ekonomik büyüme düzeyi yakalamalarını önemli ölçüde güçleştirmektedir. Mayıs 2013'te Fed'in açıklamaları ile sıkıntıya giren Hindistan, Brezilya, Endonezya, Türkiye ve Güney Afrika'nın ulusal paraları, dolar karşısında hızla değer kaybetmeye başlamıştır (Eğilmez, 2013). Kırılgan beşli ülkelerinin merkez bankaları hızla değer kaybeden ulusal paralarını koruyabilmek adına faiz oranlarını yükseltme yolunu seçmiştir. Ancak bu durum spekülatif sermaye akımlarına ve yüksek faizle borçlanmaya sebep olmuş, bu da ulusal paranın değer kaybetmesini hızlandırmıştır (Steiner, 2013).

Görüldüğü üzere tasarruf-yatırım açığı, ülkelerin makroekonomik büyüklüklerini önemli ölçüde etkileme potansiyeline sahiptir ve bu konunun detaylı şekilde incelenmesinde ve gündemde tutulmasında yarar vardır. Bu kapsamda çalışmanın amacl; kırılgan beşli ülkelerinin tasarruf-yatırım açıkları ve ekonomik büyümeleri arasındaki ilişkiyi, 1980-2013 dönemi verilerini kullanarak, yeni nesil zaman serileri yöntemleri ile analiz etmektir. Bu çerçevede ikinci bölümde; çalışmanın teorik çerçevesi sunulmuş, üçüncü bölümde; kırılgan beşlide yatırım tasarruf açığı ve ekonomik büyüme arasındaki ilişki incelenmiş, dördüncü bölümde; ilgili literatür özeti sunulmuş, beşinci bölümde ekonometrik analiz gerçekleştirilmiş ve sonuç ve önerilerle çalışma tamamlanmıştır. Bu çalışmayla, politika yapıcıların ve ekonomistlerin dikkatinin bir kez daha bu konuya çekilmesi hedeflenmektedir. İncelenen konunun ve kullanılan analiz yöntemlerinin güncelliği itibariyle çalışmanın literatüre bir katkı sağlayacağı değerlendirilmektedir.

\section{TEORIK ÇERÇEVE}

Ekonomi literatüründe yer alan birçok çalışmada, tasarruf-yatıım dengesinin negatif yönde bozulmasının, cari açığa neden olduğu belirtilmektedir (Sachs, 1981; Obstfeld, 1982a; Svensson ve Razin, 1983; Bernanke, 2005; Feyrer ve Shambaugh; 2012). Ulusal tasarruf ve yatırımlar arasındaki farklılıklar sadece anahtar makro değişkenler olarak değerlendirilmemekte; doğrudan sistemik etkileri ile ülkelerin finansal gelişmelerini de yansitabilmektedir (Obstfeld, 2012). Öyle ki ülkelerin tasarruf-yatırım dengesini belirleyen faktörler, söz konusu ülkelerin yabancı sermaye tarafından tercih edilmesi için gerekli kriterler olarak tanımlanabilmektedir (Cheung vd., 2013).

$\mathrm{Bu}$ kapsamda dinamik tasarruf ve yatırım kararlarının ileriye yönelik bir sonucu olan cari açık dengesini açıklamak için kullanılan bir model olarak karşımıza çıkan zamanlararası optimizasyon yaklaşımı; ilk olarak 1980'lerin başında Buiter (1981), Sachs(1981) ve Obstfeld (1982b) tarafindan cari denge analiz literatürüne dahil edilmiştir. Bu yaklaşımda öncelikle optimum cari açık belirlenerek, gerçekleşen cari açık ile karşılaştırılması yapılmakta ve nihayetinde politika önerileri belirlenmektedir. $\mathrm{Bu}$ yaklaşımda hane halkının zamanlararası fayda fonksiyonu, gelecekte beklenen faydalara bağlı olarak, şu şekilde ifade edilebilmektedir:

$U=E_{t}\left\{\sum_{t=\tau}^{\infty} \beta^{t-\tau}\left[U\left(C_{t}\right)\right]\right\}$

Burada $E_{t}$ beklenen değer operatörü, $\beta$ gelecek tercihini gösteren indirim faktörüdür ve $0<\beta<1$ 'dir. Denklem (1)'de verilen fayda toplamı, Mercan ve Göçer (2012)'in gösterdiği gibi, zamanlararası bütçe kısıtı altında, türev alınarak maksimize edilirse, optimum tüketim $\left(C_{t}^{*}\right)$ için şu ifadeye ulaşılır:

$$
C_{t}^{*}=r B_{t}+\left(\frac{r}{1+r}\right)\left\{\sum_{t=\tau}^{\infty}\left(\frac{1}{1+r}\right)^{t-\tau} E_{t}\left(Y_{t}-I_{t}-G_{t}\right)\right\}
$$

Burada, net dış varlıklardan sağlanan net getiriyi (dış borcu olan ülkelerde, dış borç faizini), geliri, yatırımı ve kamu harcamasını ifade etmektedir. Denklem (2)'deki ifadesi $C A_{t}=r_{t} B_{t}+Y_{t}-C_{t}-I_{t}=S_{t}-I_{t}$ eşitliğindeki $C_{t}$ yerine, yazılırsa, optimum cari denge elde edilir: 


$$
C A_{t}^{*}=Y_{t}-\left(\frac{r}{1+r}\right)\left\{\sum_{t=\tau}^{\infty}\left(\frac{1}{1+r}\right)^{t-\tau} E_{t}\left(Y_{t}-I_{t}-G_{t}\right)-G_{t}-I_{t}\right\}
$$

Bir $X$ değişkeni için uzun dönem değeri $X^{*}$ ve $X^{\prime}$ in uzun dönem beklenen değeri $E X^{*}$ olmak üzere, şu tanımlamalar yapılabilir:

$X_{t}^{*}=\left(\frac{r}{1+r}\right) \sum_{t=\tau}^{\infty}\left(\frac{1}{1+r}\right)^{t-\tau} X_{t} \quad$ ve $\quad E X_{t}^{*}=\left(\frac{r}{1+r}\right) \sum_{t=\tau}^{\infty}\left(\frac{1}{1+r}\right)^{t-\tau} E_{t} X_{t}$

Bu tanımlardan faydalanarak optimum cari denge şu şekilde yazılabilir.

$$
C A_{t}^{*}=\left(Y_{t}-E_{t} Y_{t}^{*}\right)-\left(I_{t}-E_{t} I_{t}^{*}\right)-\left(G_{t}-E_{t} G_{t}^{*}\right)
$$

Bu denklemde $Y_{t}^{*}$ uzun dönemde beklenen geliri, $I_{t}^{*}$ yatırımı ve $G_{t}{ }^{*}$ kamu harcamasını belirtmektedir. Denklem (4) temsili hane halkının dinamik optimizasyon işleminden elde edilen optimum cari açık düzeyini ifade etmektedir. Zamanlararası optimizasyon yaklaşımı, tasarruf ile cari açık arasında güçlü bir ilişki öngörmektedir. Böyle bir ilişki geçerli ise:

$$
C A_{t}=\alpha+\beta S_{t}+u_{t}
$$

Denklemi tahmin edildiğinde, nın bire yakın çıkması gerekir. $C A_{t}=S_{t}-I_{t}$ eşitliği, denklem (6)'da yerine yazılarak yeniden düzenlendiğinde:

$$
S_{t}=\theta+\varphi I_{t}+\varepsilon_{t}
$$

şekline gelir. Burada 'nin birden büyük olması; ülkenintasarruflarının,yatırımlarındanfazla olduğunu, yani cari işlemler açığının sürdürülebilir olduğunu ifade etmektedir (Mercan ve Göçer, 2012). Cari açık sorunu ortadan kalktığında ise ekonomik büyüme hızlanacak ve istikrarlı bir hal alacaktır. Görüldüğü üzere, ulusal tasarrufların artması ve tasarruf-yatırım açığının azalması, ekonomik büyümeyi arttırıcı bir faktör olarak karşımıza çıkmaktadır. Bu durum aşağıdaki şekilde formüle edilebilecektir:

$$
G_{t}=\aleph_{0}+\aleph_{1} S I_{t}+\omega_{t}
$$

Burada ile eşbütünleşik olmak koşuluyla, 'in işaretinin negatif olması beklenmektedir. Tasarrufyatırım dengesinin ekonomik büyümeyi etkileme kanalları, Kalkınma Bakanlığı (2012) çalışmasından yararlanarak ve tarafımızdan geliştirilerek oluşturulan Şekil 1 yardımıyla incelenebilir.

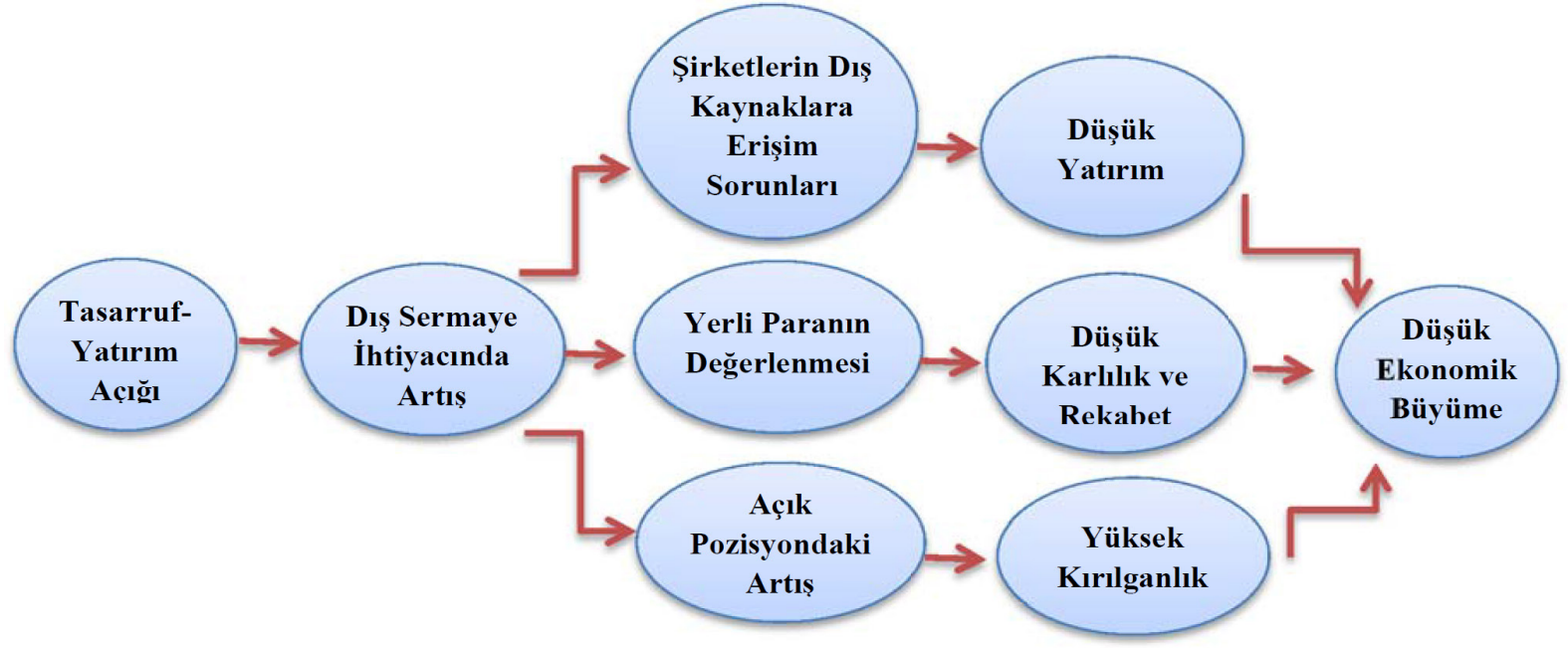

Şekil 1: Tasarruf-Yatırım Açığından Ekonomik Büyümeye Potansiyel Geçiş Kanalları

Şekil 1'e göre; artan tasarruf-yatırım açığı, ülkenin dış sermayeye olan ihtiyacını arttırmakta, bu durumda şirketlerin dış finansmana erişim sorunları, yerli paranın değerlenmesi ve açık pozisyon artışı sorunları yaşanmakta, bu gelişmeler firmaların yatırımlarını azaltmasına, karlılıklarının ve rekabet güçlerinin azalmasına ve finansal kırılganlıklarının artmasına neden olmakta ve bütün bu olayların sonucunda ise ekonomiler düşük bir ekonomik büyüme performansı sergileyebilmektedirler. 


\section{KIRILGAN BEŞLIDE YATIRIM TASARRUF AÇIĞI VE EKONOMIK BÜYÜME}

Brezilya, Hindistan, Endonezya, Güney Afrika ve Türkiye'nin içinde yer aldığı Kırılgan beşli ülkelerinin ekonomi literatürüne bir anda kırılgan olarak geçmesinin ana sebeplerinden biri söz konusu ülkelerin gelişmelerinin büyük ölçüde yabancı yatırımlara bağlı olmasıdır. Fed Başkanı Bernanke' nin 22 Mayıs 2013 tarihinde yaptığı açıklamalardan sonra, uluslararası fon piyasasında düşük maliyetli paranın azalacağı endişesi, buna ilave olarak Çin'in gelişmekte olan ülkelere yapmış olduğu yatııımları azaltması, yükselen piyasa ekonomilerini önemli ölçüde etkilemiştir. İş ve Ekonomi Araştırmaları Merkezi'nin (CEBR) her yıl yayımlamakta olduğu Dünya GSYH Değerlendirme Tablosu 2014 verilerine göre sırasıyla dünyanın en büyük ekonomiye sahip ilk
30 ülkesi arasında Brezilya 7. Hindistan 9. Endonezya 16. ve Türkiye 19. sırada yer almaktadır. Ancak söz konusu olumlu tablo kişi başına düşen gelir rakamı analiz edildiğinde başka bir hal almaktadır. OECD'nin yayınlamış olduğu Economic Surveys Brazil 2013 raporuna göre gelir dağılımının eşitsiz dağıldığı ülkeler arasında Güney Afrika 1 inci, Brezilya 3 üncü, Endonezya 15 inci, Hindistan 18 inci sırada yer almaktadır.

Kırılgan Beşli ülkelerinin yatırım tasarruf açığı, büyüme, net sermaye girişleri ve döviz kurundaki gelişimler Tablo 1'de sunulmuştur. Tablo 1 oluşturmak için elde edilen veriler IMF Dünya Ekonomi Raporu 2014, Dünya Bankası veri tabanı, kırılgan beşli ülkelerinin Merkez bankalarının istatistik birimleri ve Euromoney Institutional Investor Company (CEIC) kaynaklarından faydalanarak oluşturulmuştur.

Tablo 1: Kırılgan Beşlide Ekonomik Göstergelerin Karşılaştırılması

\begin{tabular}{|c|c|c|c|c|c|c|c|}
\hline Brezilya & 2001 & 2005 & 2010 & 2011 & 2012 & 2013 & 2014 \\
\hline Tasarruf-Yatııım Açığı/GSYH (\%) & -4.1 & 1.5 & -2.2 & -2.1 & -2.4 & -3.6 & -3.5 \\
\hline Büyüme (\%) & 1.3 & 3.1 & 7.5 & 2.7 & 1.1 & 2.4 & 0.3 \\
\hline Net Sermaye Girişi/GSYH (\%) & 4.1 & 1.7 & 2.5 & 2.9 & 3.4 & 3.6 & 2.6 \\
\hline BRL/USD & 2.35 & 2.43 & 1.76 & 1.67 & 1.95 & 2.16 & 2.45 \\
\hline Endonezya & 2001 & 2005 & 2010 & 2011 & 2012 & 2013 & 2014 \\
\hline Tasarruf-Yatııım Açı̆̆ı/GSYH (\%) & 4.3 & 0.5 & 0.7 & 0.2 & -2.7 & -3.3 & -3.2 \\
\hline Büyüme (\%) & 3.6 & 5.6 & 6.2 & 6.4 & 6.2 & 5.7 & 5.1 \\
\hline Net Sermaye Girişi/GSYH (\%) & -1.8 & 2.9 & 2.2 & 2.4 & 2.4 & 2.6 & 2.5 \\
\hline IRD/USD & 10260 & 9704 & 9090 & 8770 & 9386 & 10461 & 11818 \\
\hline Hindistan & 2001 & 2005 & 2010 & 2011 & 2012 & 2013 & 2014 \\
\hline Tasarruf/Yatırım Açığı /GSYH (\%) & 0.6 & -1.2 & -2.7 & -4.2 & -4.7 & -1.7 & -2.1 \\
\hline Büyüme (\%) & 4.8 & 9.3 & 10.2 & 6.6 & 4.7 & 5.1 & 5.6 \\
\hline Net Sermaye Girişi/GSYH (\%) & 1.1 & 0.8 & 1.6 & 1.9 & 1.3 & 1.5 & 1.4 \\
\hline RP/USD & 47.19 & 44.10 & 45.73 & 46.67 & 53.44 & 58.60 & 63.47 \\
\hline Güney Afrika & 2001 & 2005 & 2010 & 2011 & 2012 & 2013 & 2014 \\
\hline Tasarruf-Yatııım Açığı/GSYH (\%) & 0.3 & -3.5 & -1.9 & -2.3 & -5.2 & -5.8 & -5.7 \\
\hline Büyüme (\%) & 1.3 & 3.2 & 7.5 & 2.7 & 1.1 & 2.5 & 1.5 \\
\hline Net Sermaye Girişi/GSYH (\%) & 6.1 & 2.6 & 1.1 & 1.1 & 1.2 & 2.3 & 1.6 \\
\hline ZAR/USD & 8.61 & 6.36 & 7.32 & 7.26 & 8.21 & 9.66 & 11.29 \\
\hline Türkiye & 2001 & 2005 & 2010 & 2011 & 2012 & 2013 & 2014 \\
\hline Tasarruf-Yatıım Açığı/GSYH (\%) & 1.9 & -4.4 & -6.2 & -9.7 & -6.2 & -7.9 & -7 \\
\hline Büyüme (\%) & -5.7 & 8.4 & 9.7 & 8.7 & 2.1 & 4.1 & 2.9 \\
\hline Net Sermaye Girişi/GSYH (\%) & 1.7 & 2.1 & 1.2 & 2.1 & 1.6 & 1.6 & 1.5 \\
\hline TRY/USD & 1.23 & 1.34 & 1.50 & 1.67 & 1.80 & 1.90 & 2.19 \\
\hline
\end{tabular}


Tablo 1'de Brezilya'nın 2001-2014 yılları arasında genel olarak tasarruf yatırım açığı verdiği, tasarruf-yatırım açığı değerleriyle, net sermaye girişi değerlerinin de eş-anlı hareket ettiği, yani ülkede oluşan tasarruf açığının, sermaye girişleriyle kapatılmaya çalışıldığı ve büyümelerinin yurtdışı sermaye girişleri ile finanse edildiği görülmektedir. Ekonomik büyüme oranı genel olarak düşük olan bu ülkede, 2010'da görülen yüksek oranın da kriz sonrası oluşan baz etkisi nedeniyle ortaya çıktığı düşünülmektedir. 2008 küresel kriz Brezilya ekonomisini kırılgan hale getirmiş ve sermaye şoklarına karşı daha ciddi önlemler alması gerektiği hususunda uyarı niteliğinde algılanmıştır (IMF, 2012). Bu ülkelerin ekonomik büyümeleri 2010 yılından önemli ölçüde düşük büyüme eğilimine girerek, kırılganlık sinyali vermeye başlamıştır (Kynge, 2014). Ülkelerin ulusal para/ USD kurları incelendiğinde; ülkelerin ulusal paralarının 2011 yılı sonrasında genel olarak değer kaybettiği gözlemlenmektedir. Ülkelerin ulusal paralarını desteklemek adına uyguladığı heteredoks para politikaları ülkelerin kur riskini tetiklemiştir (Morgan Stanley, 2013). Özellikle Türkiye Merkez Bankasının Ocak 2014' te faiz oranlarını bir anda \% 4.25 oranında artırması, kırılgan beşli ülkeleri arasında en kırılgan ülkenin Türkiye olduğu hususunda yorumlara neden olmuştur (Landon, 2014). Uluslararası derecelendirme kuruluşu Moody's'in 24 Mart 2015 tarihli değerlendirmesine göre; dolardaki yükseliş sebebiyle Türk şirketlerinin dış borçlarını ödemeleri daha da zorlaşmıştır. Artan kurla birlikte Türkiye gibi yüksek dış borcu bulunan ülkelerde ödemelerin daha maliyetli olacağını belirten Moody's, Türkiye'nin en kırılgan ülke olarak öne çıktığını ifade etmiştir.

\section{LITERATÜR ÖZETi}

Yüksek tasarruf oranlarının, yüksek yatırımlara sebep olduğu ve bu durumun, ekonomik büyümeyi tetiklediği, literatürde yaygın biçimde kabul edilen bir gerçektir (Solow, 1956; Cass, 1965; Koopmans, 1965; Romer,1986; Bacha,1990; De Gregorio,1992; Jappelli ve Pagano, 1994; Deaton ve Paxson, 2000; Van vd., 2014). Tasarruflar ekonomik büyüme süreci için belirgin bir kaynak ve ulusal yatırımların finansmanı için en önemli tedarikçi olarak görülmektedir (Cullison, 1993; Looney,1996). Bununla birlikte Romer (1990), Aghion ve Howitt'e (1992) göre ise teknolojik gelişme büyüme için ana lokomotif olarak görülmekte ve sermaye birikimi göz ardı edilmektedir.
Howitt ve Aghion (1998) daha sonra yayınladıkları çalışmalarında konuyu revize ederek, sermaye birikimi ve teknolojik gelişme arasında bütünleyici bir ilişki olduğunu; büyüme dengesinin ulusal tasarruflar üzerinde pozitif bir etkisi olduğu sonucuna varmış; ancak bu teorinin açık ekonomilerde pek mümkün olmadığını vurgulamıştır. Gelişmekte olan ve tasarruf açığı veren ülkelerin yatırımları ve dolayısıyla büyümeleri yurtdışı doğrudan yatırımlarla mümkün olabilmektedir. Bu durumun doğal sonucu olarak ulusal yatırımlar azalmakta ve ülkenin gelişme ve ilerleme için dışa bağımlılığı giderek artmaktadır. Prasad vd. (2007) gelişmekte olan ülkeler için yapmış oldukları deneysel analizin neticesinde yüksek dışa açıklık oranı ve sermaye akımının, yüksek büyümeye sebep olmadığı sonucuna varmışlardır. Elde edilen bu sonuç, gelişmekte olan ülkelerin finansal piyasalarının az gelişmiş olması sebebiyle, dış kaynakları etkin bir biçimde massedebilme durumunun sınırlı olması ile açıklanabilmektedir (Mohan, 2008). Lane ve Pels (2012) Avrupa ülkelerini kapsayan çalışmalarında, sermaye akımlarının artan elastikiyetiyle tutarlı olarak, özellikle 2002-2007 yılları arasında, büyüme tahminleri ile tasarruf eksikliği arasındaki ilişkinin güçlenerek arttığı hususuna vurgu yapmıştır. Söz konusu ilişkinin yönü ve istikrarlılığı ayrı bir önem arz etmektedir. Şayet istikrarlı tasarruf nedenli büyüme ilişkisi söz konusu ise büyüme politikalarını belirlerken, tasarrufu teşvik etmek önemli bir ölçüt olacaktır (Tang ve Chua, 2012).

\section{EKONOMETRIK ANALIZ}

\subsection{Veri seti}

Bu çalışmada; Kırılgan Beşlide ulusal tasarruf eksiğinin ekonomik büyümeye etkileri, 1980-2013 dönemi Brezilya, Endonezya, Hindistan, Güney Afrika ve Türkiye için tasarruf-yatırım dengesi ((S-I)/GSYH) ve büyüme ( $\% \mathrm{GSYH}$ ) verileri kullanılarak analiz edilmiştir. Veriler Dünya Bankası ve IMF'nin web sitelerinden temin edilmiştir.

\subsection{Model}

Bu çalışmada tasarruf-yatırım dengesinin (SI) büyüme (G) üzerindeki etkisi Kırılgan Beşli ülkeleri için ayrı ayrı analiz edilmiş ve her bir ülke için aşağıdaki model tahmin edilmiştir:

$$
G_{t}=\aleph_{0}+\aleph_{1} S I_{t}+\mu_{t}
$$




\subsection{Yöntem}

$\mathrm{Bu}$ çalışmada serilerin durağanlığı; Kapetanios (2005) çoklu yapısal kırılmalı birim kök testiyle, seriler arasındaki nedensellikilişkileri Toda-Yamamoto (1995) nedensellik testiyle, seriler arasında eşbütünleşme ilişkisinin varlığı Maki (2012) testiyle, uzun ve kısa dönem ilişkileri dinamik en küçük kareler (Dynamic Ordinary Least Squares: DOLS) yöntemiyle tahmin edilmiştir.

\subsection{Kapetanios (2005) Çoklu Yapısal Kırılmalı Birim Kök Testi}

Birim kök testi analizleri ekonomik olayların etüt edilmesinde olmazsa olmaz ön koşullardan biri olmuştur. Bu bağlamda yapılan çalışmalar zamanla geliştirilmiş ve Perron(1989) ile birlikte birim kök testi analizlerine yapısal kırılmalar ve bu kırılmaların sonuçları dâhil edilmiştir. Banerjee vd., (1992) ve ZivotAndrews (1992) tek yapısal kırılmaya; LumsdainePapell (1997), Perron (1997), Ng-Perron (2001) ve LeeStrazicich (2003) iki tane yapısal kırılmaya izin veren birim kök testi analizleri geliştirmiştir. Kapetanios (2005) çoklu yapısal kırılmalı birim kök testi yöntemi beş taneye kadar yapısal kırılmaya izin vermekte ve bu yöntemle kırılma sayısı ve kırılma tarihleri içsel olarak belirlenebilmektedir. Bu testte kullanılan model aşağıdaki gibidir (Kapetanios, 2005):

$$
\begin{aligned}
& G_{t}=\alpha_{0}+\alpha_{1} t+\beta G_{t-1}+\sum_{i=1}^{p} \gamma_{i} \square G_{t-i}+\sum_{i=1}^{m} \varphi_{i} S I_{i, t}+\dot{o}_{t} \\
& D U_{i, t}=\left\{\begin{array}{rr}
1 & t>T_{b, i} \\
0 & \text { Diger Durumlarda }
\end{array} \text { ve } D T_{i, t}=\left\{\begin{array}{rr}
t-T_{b, i} & t>T_{b, i} \\
0 & \text { Diger Durumlarda }
\end{array}\right.\right.
\end{aligned}
$$

Burada DU; sabit terimde (düzeyde) meydana gelen yapısal kırılmayı, DT ise trendde (eğimde) meydana gelen kırılmayı belirlemeye yönelik kukla değişkenler olup, testin boş hipotezi; " $\beta=1$ yani seri durağan değildir" şeklindedir. Uygulanan test nihayetinde elde edilen sonuçlar, Tablo 2'de sunulmuştur.

\begin{tabular}{|c|c|c|c|c|}
\hline & & t- istatistiği & Kritik Değer (\%1) & Yapısal Kırılma Tarihleri \\
\hline \multirow{2}{*}{ Brezilya } & G & -4.95 & -5.65 & $2000-2007$ \\
\hline & SI & -4.32 & -5.33 & 2002 \\
\hline \multirow{2}{*}{ Endonezya } & G & -4.37 & -5.61 & 1998-2008 \\
\hline & SI & -4.75 & -5.33 & 1993 \\
\hline \multirow{2}{*}{ Güney Afrika } & $G$ & -4.71 & -6.16 & 1993-2009 \\
\hline & SI & -4.45 & -5.33 & 1992 \\
\hline \multirow{2}{*}{ Hindistan } & G & -5.80 & -6.16 & 1998-2006 \\
\hline & SI & -4.45 & -5.61 & $2002-2007$ \\
\hline \multirow{2}{*}{ Türkiye } & $G$ & -4.15 & -5.01 & 2002 \\
\hline & SI & -4.66 & -5.33 & 2004 \\
\hline \multirow{2}{*}{ Brezilya } & $\Delta G$ & $-6.69 * * *$ & -6.16 & 2002-2011 \\
\hline & $\Delta S I$ & $-5.81^{* * *}$ & -5.33 & 2000 \\
\hline \multirow{2}{*}{ Endonezya } & $\Delta G$ & $-7.37^{* * *}$ & -5.33 & 1999 \\
\hline & $\Delta S I$ & $-6.73^{* * *}$ & -5.33 & 2001 \\
\hline \multirow{2}{*}{ Güney Afrika } & $\Delta G$ & $-6.75^{* * *}$ & -5.01 & 2009 \\
\hline & $\Delta S$ & $-5.83^{* * *}$ & -5.01 & 1996 \\
\hline \multirow{2}{*}{ Hindistan } & $\Delta G$ & $-7.37^{* * *}$ & -5.61 & 1993-2012 \\
\hline & $\Delta S I$ & $-9.09 * * *$ & -6.16 & $2007-2013$ \\
\hline \multirow{2}{*}{ Türkiye } & $\Delta G$ & $-10.69^{* * *}$ & -5.65 & 2004-2012 \\
\hline & $\Delta S I$ & $-7.50^{* * *}$ & -4.89 & 2004 \\
\hline
\end{tabular}

Tablo 2: Kapetanios (2005) Birim Kök Testi Sonuçları

Not: *** \%1 önem düzeyinde serilerin durağanlıklarını ifade etmektedir. Test istatistikleri Gauss programı için yazılmış kodlarla elde edilmiştir. Kritik değerler, bootstrap yardımıyla 1000 yineleme ile elde edilmiştir. Test yöntemi olarak, yapısal kırılma sayısını veri setine göre belirleyen model seçilmiştir. 
Tablo 2'deki sonuçlar incelendiğinde; serilerin düzey değerlerinde birim kök içerdiği, yani durağan olmadığı, ancak birinci farkları alındığında durağan hale geldikleri yani I(1) oldukları görülmektedir. Bu test yöntemi tarafından belirlenen yapısal kırılma tarihlerinin, ülkelerin ekonomilerindeki ekonomik şoklar ile uyumlu olduğu görülmektedir. Ülkelere bakıldığında Brezilya; 2000'li yılların başlarında yaşadığı siyasi belirsizlikler ve 2001 Arjantin borç krizinin de etkisiyle, 2002'de bir yapısal kırılma yaşamış, bunu 2008 küresel krizinin etkileri izlemiştir. Endonezya ekonomisinin yapısal kırılma tarihlerine bakıldığında 1993; Endonezya'nın bir dizi ekonomik önlemler alarak, çok boyutlu bir dış politika izlemeye başladığı dönemin başlangıcını, 1998; 1997 Güney Asya krizi nedeniyle ekonomide yaşanan sıkıntılara, ulusal parasının \%40 değer kaybetmesine ve bu yılda yaşanan \%13'lük ekonomik küçülmeye işaret etmektedir. 2008 ise küresel ekonomik krizin izlerini barındırmaktadır. Güney Afrika'nın yapısal kırılma tarihleri olarak; 1993 ve 2009 öne çıkmaktadır. 1990'ı yılların başında bu ülkede büyük kargaşalara yol açan ırk ayrımcılığı sistemin izlerini silmek için çalışmalara başlamış ve bu sayede politik ve ekonomik olarak küresel tecritten kurtulmuştur. Nelson Mandela tarafından uygulanmaya başlayan Yeniden Yapılanma ve Kalkınma Programı ile değerli maden kaynaklarına sahip ülke yeniden dünya finans piyasalarına girmeye başlamış ve 1993 yılı sonrasında ülke ekonomisi büyüme eğilimine girmiştir. Diğer bir yapısal kırılma tarihi olan 2009 yılında ise 2008 küresel krizinin etkileri görülmektedir. Hindistan'ın yapısal kırılma tarihlerinin 1998, 2002 ve 2006 yılları olduğu görülmektedir. 1998; siyasi istikrarsızlık,2001'e kadar süren yüksek bütçe açıkları ve Güney Asya krizinin etkilerini, 2002; Çin'in 2001'de Dünya Ticaret Örgütüne girmesiyle birlikte Hindistan'ın dış piyasalarda pazar kayıpları yaşamasının etkilerini (Öz, 2007) ve 2006;
2003 yılından itibaren bu ülkede yaşanan siyasi istikrar, teknolojik alt yapı yatırımları, bürokratik engellerin ortadan kaldırılması ve yapısal reformlar ile birlikte Çin ile beraber en yüksek doğrudan yabancı yatırımları çeken ülkesi haline gelmesinin etkilerini yansıtmaktadır. Son olarak Türkiye ekonomisinde; 2002 ve 2004 yılları ön plana çıkmıştır. Türkiye'de yaşanan 2001 krizi sonrası, Nisan 2001'de ilan edilen Güçlü Ekonomiye Geçiş Programı, 2002 sonrası dönemde dünyada yaşanan likidite bolluğu ve ülkede başlayan tek parti iktidarının da etkisiyle Türkiye ekonomisi, 2002 yılı sonrasında güçlü bir büyüme eğilimine girmiştir. 2004 yılı ve sonrasında uygulanan düşük faiz politikası nedeniyle artan iç talep ve düşen yurtiçi tasarruflar nedeniyle, tasarruf- yatırım dengesi negatif yönde artmaya devam etmiştir.

\subsection{Toda Yamamoto (1995) Nedensellik Testi}

Kırılgan Beşli ülkelerinin büyüme oranları ve tasarruf dengesi arasındaki nedensellik ilişkisinin dayanıklı (robust) sonuçlar üretebilmesi için çalışmanın bu bölümünde Toda-Yamamoto (1995) nedensellik testi (TY)'ne yer verilmiştir. TY yönteminde seriler durağanlık ve eşbütünleşme gibi bilgilere gerek kalmaksızın analize dâhil edilebilmekte ve bu durum bilgi ve gözlem kaybını azaltabilmektedir.

TY yöntemi uygulanırken ilk olarak VAR modelinde uygun gecikme uzunluğu (k) tespit edilir. Ikinci aşamada, $k$ gecikmeye, en yüksek bütünleşme derecesine sahip değişkenin bütünleşme seviyesi $\left(d_{\text {max }}\right)$ ilave edilmektedir. Her iki serinin de I(0) olması durumunda TY testi, Granger (1969) nedensellik testi ile benzerlik göstermekte VAR modeline gecikme uzunluğu eklenmemektedir (Yılancı ve Özcan, 2010). Üçüncü aşamada, $\left(k+d_{\max }\right)$ gecikme için serilerin düzey değerleriyle VAR modeli tahmin edilmektedir. Bu aşamada tahmin edilecek olan VAR modeli beş ülke için benzer şekilde olup, aşağıdaki gibidir:

$$
\begin{aligned}
& G_{t}=\alpha_{0}+\sum_{i=1}^{p+d_{\max }} \alpha_{1 i} G_{t-i}+\sum_{i=1}^{p+d_{\max }} \alpha_{2 i} S I_{t-i}+\mu_{t} \\
& S I_{t}=\beta_{0}+\sum_{i=1}^{p+d_{\max }} \beta_{1 i} S I_{t-i}+\sum_{i=1}^{p+d_{\max }} \beta_{2 i} G_{t-i}+\mu_{t}
\end{aligned}
$$


Son aşamada; 'tan gelen katsayılara kısıtlar konur ve MWALD testi ile bu kısıtların anlamlılığı sınanır. Denklem (13) için testin boş hipotezi; Sl'dan G'ye, Denklem (14) için ise Sl'dan G'ye doğru bir nedensellik ilişkisinin olmadığı şeklindedir.

Bu çalışmada, TY testini uygulamak için önce serilerin düzey değerleriyle bir VAR modeli tahmin edilmiş ve buradan optimum gecikme uzunluğu Schwarz ve Hannan-Quinn kriterlerine göre 1 olarak belirlenmiştir. Bu gecikme uzunluğuna sahip VAR modelinde otokorelasyon ve değişen varyans sorunlarının olmadığı görülmüştür. Bu çalışmada serilerin en büyük bütünleşme derecesi $\left(d_{\max }\right) 1$ olduğu için (yani seriler en fazla I(1) olduğu için), $\mathrm{p}+\mathrm{d}_{\max }=1+1=2$ gecikmeli regresyon modelleri tahmin edilmiştir. MWALD sınaması $p=2$ gecikme üzerine uygulanmış ve elde edilen sonuçlar Tablo 3'de sunulmuştur.

Tablo 3: Toda-Yamamoto Nedensellik Testi Sonuçları

\begin{tabular}{|c|l|c|c|c|}
\hline \multirow{3}{*}{ Brezilya } & Boş Hipotez & $\begin{array}{c}\text { Gecikme Uzunluğu } \\
\mathbf{k}=\mathbf{1} \boldsymbol{d}_{\text {max }}=\mathbf{1}\end{array}$ & $\boldsymbol{x}^{\mathbf{2}}$ Istatistiği & Olasılık Değeri \\
\hline \multirow{3}{*}{ Endonezya } & $S I \nRightarrow G$ & 2 & 5.44 & 0.06 \\
\cline { 2 - 5 } & $G \nRightarrow S I$ & 2 & 0.37 & 0.83 \\
\cline { 2 - 5 } & $S I \nRightarrow G$ & 2 & 0.12 & 0.93 \\
\hline \multirow{3}{*}{ Güney Afrika } & $S I \nRightarrow G I$ & 2 & 1.31 & 0.51 \\
\cline { 2 - 5 } & $G \nRightarrow S I$ & 2 & 10.65 & 0.004 \\
\hline \multirow{3}{*}{ Hindistan } & $S I \nRightarrow G$ & 2 & 2.11 & 0.34 \\
\cline { 2 - 5 } & $G \nRightarrow S I$ & 2 & 7.78 & 0.02 \\
\hline \multirow{2}{*}{ Türkiye } & $S I \nRightarrow G$ & 2 & 5.93 & 0.05 \\
\cline { 2 - 5 } & $G \nRightarrow S I$ & 2 & 0.78 & 0.67 \\
\hline
\end{tabular}

Not: Optimum gecikme uzunluğu (k), Schwardz kriteriyle belirlenmiştir.

Tablo 3'te Brezilya ve Güney Afrika'da tasarrufyatırım açı̆̆ından ekonomik büyümeye doğru tek yönlü, Hindistan'da tasarruf-yatırım açı̆̆ı ile ekonomik büyümeye arasında çift yönlü nedensellik ilişkisi olduğu görülürken, Endonezya ve Türkiye'de tasarrufyatırım açı̆ı ile ekonomik büyümeye arasında bir nedensellik ilişkisinin olmadığı görülmektedir.

\section{6. Çoklu Yapısal Kırılmalı Eşbütünleşme Analizi}

Ekonomik değişkenler arasında denge ilişkileri yapısal kırılmalı eşbütünleşme testleri ile analiz edilmektedir. Yapısal kırılmalar, belirli bir dönem içerisinde görülen siyasi değişimleri, ekonomi birimlerinin davranışlarını ve bazı ekonomik şokları izah etmek açısından önem arz etmektedir. Bu bağlamda eşbütünleşme analizlerine dâhil edilen yapısal kırılmalar, analizlerin performansını önemli ölçüde etkilemektedir. Buyöntem, Bai ve Perron (1998) tarafından önerilen yapısal kırılmalı test ile Kapetanios (2005) birim kök testinin eşbütünleşme hali olup, beş taneye kadar yapısal kırılmanın varlığı durumunda, seriler arasındaki eşbütünleşmenin varlığını test edebilmekte, yapısal kırılma sayısını ve tarihlerini içsel olarak belirleyebilmektedir. Bu yönleriyle literatürde yer alan diğer eşbütünleşme testlerinden daha güçlüdür (Maki, 2012). Testin çalışma algoritmasında; her bir dönem muhtemel bir kırılma noktası olarak alınmakta, $t$ istatistikleri hesaplanmakta ve $t$ 'nin minimum olduğu noktalar, kırılma noktası olarak kabul edilmektedir. Bu yöntemde analize alınacak bütün serilerin I(1) olması gerekmektedir. Maki (2012), yapısal kırılmaların varlığı durumunda seriler arasında eşbütünleşme ilişkisinin varlığını araştırmak için 
düzeyde kırılmalı trendsiz model, düzey ve eğimde kırılmalı trendsiz model, düzeyde ve eğimde kırılmalı trendli model ile düzey, eğim ve trendde kırılmalı model olmak üzere dört farklı model geliştirmiştir. Testin boş hipotezi; "Yapısal kırılmalar altında seriler arasında eşbütünleşme ilişkisi yoktur" şeklindedir.
$\mathrm{Bu}$ hipotezi test etmek için gerekli olan kritik değerler, Monte Carlo simülasyonuyla hesaplanmış ve Maki'de (2012) verilmiştir. Çalışmamızda seriler arasında eşbütünleşme ilişkisinin varlığı, Maki (2012) yöntemiyle araştırılmıştır ve elde edilen sonuçlar, Tablo 4'te sunulmuştur.

Tablo 4: Maki Eşbütünleşme Testi Sonuçları

\begin{tabular}{|l|c|l|}
\hline & Test İstatistiği & Yapısal Kırılma Tarihleri \\
\hline Brezilya & $-9,80^{* * *}$ & $1983,1987,1994,2000,2010$ \\
\hline Endonezya & $-8,11^{* * *}$ & $1989,1998,2001,2004$ \\
\hline Güney Afrika & $-6,19^{*}$ & $1984,1999,2008$ \\
\hline Hindistan & $-6,39^{* * *}$ & $1995,2001,2008$ \\
\hline Türkiye & $-6,79^{* *}$ & $1988,2005,2008,2011$ \\
\hline
\end{tabular}

Not: Kritik değerler, Maki (2012, s. 2013) Tablo 1'den alınmıştır. * ** ve *** sırasıyla \%10,\%5 ve \%1 anlamlılık düzeyinde seriler arasında eşbütünleşme ilişkisinin varlığını ifade etmektedir. Test modeli olarak; Brezilya için Model 3,Hindistan için Model 1, diğer ülkeler için Model 2 kullanılmıştır.

Tablo 4'teki sonuçlar incelendiğinde, kırılgan beşli ülkeleri için seriler arasında eşbütünleşme ilişkisinin var olduğu görülmektedir. Eşbütünleşme ilişkisinin varlığı; tasarruf-yatırım açığı ve büyüme serilerinin uzun dönemde birlikte hareket ettiğini ve düzey değerleriyle gerçekleştirilecek uzun dönem analizlerinde, sahte regresyon problemiyle karşılaşılmayacağını ifade etmektedir. Testin belirlediği yapısal kırılma tarihleri incelendiğinde Brezilya için; 1994 Meksika krizi, 1999 yılı Brezilya ülke krizi ve 2004 yılında Brezilya ve Çin arasında yaşanan ticari ve ekonomik yakınlaşma ile Çin'in, Brezilya'nın en büyük ticari ortağı haline gelmesine işaret ederken, Endonezya da; 1989'da dış ticarette hükümet denetimlerinin kaldırmış olması, 1997 Güney Asya krizi ve 1999-2004 yılları arasında demokratikleşme sürecine ve yapısal reformlara ağırlık verilmesinin etkilerini yansıtmaktadır. Güney Afrika için 1984; ülkede yaşanan iç kargaşa ve ırkçı politikalara karşı direniş hareketlerine, 1999; 1997 Güney Asya krizi ve 1998 Rusya borç krizlerinin etkilerine ve 2008; küresel ekonomik krizin bu ülkeye olan etkilerine işaret etmektedir. Hindistan için 1995; Hindistan'ın Dünya Ticaret Örgütüne girmesine, 2001; Çin'in Dünya Ticaret Örgütü'ne dâhil olmasına ve 2008; küresel ekonomik krizin bu ülkeye olan etkilerine işaret etmektedir.

Türkiye'nin kırılma tarihlerine bakıldığında ise 1988; bütçe açıklarındaki artış ve mali piyasalardaki dalgalanmayla birlikte faizlerin yükseldiği, yatırımları azalttığı ve ekonomik büyümenin durma noktasına geldiği döneme, 2005; dünyada yaşanan likidite bolluğunun etkisiyle Türkiye'ye gelen dış sermaye miktarındaki artışların da etkisiyle ekonominin \%9.36 büyüdüğü döneme, 2008; Küresel Krizin etkilerine ve 2011; krizden çıkış sürecinde uygulanan genişletici para politikalarının sonlandırılmaya başlandığı döneme işaret etmektedir. Elde edilen bu yapısal kırılma tarihleri, kukla değişkenlerle uzun dönem analizine dâhil edilmiştir.

\subsection{Uzun Dönem Analizi: Eşbütünleşme Katsayılarının Tahmini}

Serilerin uzun dönem analizi Saikonen (1991) ve Stock-Watson (1993) tarafından geliştirilen DOLS yöntemi ile tahmin edilmiştir. Bu yöntem modele bağımsız değişkenlerin düzey değerlerinin yanı sıra serilerin farkları ve öncül değerlerini de dâhil etmesi yönüyle, diğer yöntemlerden güçlü kabul edilmektedir (Stakénas, 2010). Analiz sonucunda elde edilen bulgular Tablo 5'te sunulmuştur. 
Tablo 5: Uzun Dönem Eşbütünleşme Katsayıları

\begin{tabular}{|l|c|c|c|c|c|c|c|c|c|c|}
\hline $\begin{array}{l}\text { Bağımlı } \\
\text { Değişken }\end{array}$ & $\begin{array}{c}\text { Sabit } \\
\text { Terim }\end{array}$ & $\mathbf{S I}$ & $\boldsymbol{K}_{\mathbf{1}}$ & $\boldsymbol{K}_{\mathbf{2}}$ & $\boldsymbol{K}_{\mathbf{3}}$ & $\boldsymbol{K}_{\mathbf{4}}$ & $\boldsymbol{K}_{\mathbf{5}}$ & $\boldsymbol{R}^{2}$ & $\overline{\boldsymbol{R}}^{2}$ & $\boldsymbol{J} \boldsymbol{B}$ \\
\hline Brezilya & 1.7 & $\begin{array}{c}-2.96^{* * *} \\
{[-4.56]}\end{array}$ & $\begin{array}{c}-2.30 \\
{[-0.81]}\end{array}$ & $\begin{array}{c}-3.79^{* *} \\
{[-1.85]}\end{array}$ & $\begin{array}{c}19.01^{* * *} \\
{[4.85]}\end{array}$ & $\begin{array}{c}-26.69^{* * *} \\
{[-5.13]}\end{array}$ & $\begin{array}{c}24.26^{* * *} \\
{[5.44]}\end{array}$ & 0.90 & 0.54 & 0.11 \\
\hline Endonezya & -2.75 & $\begin{array}{c}-0.51^{* * *} \\
{[-2.88]}\end{array}$ & $\begin{array}{c}-2.30 \\
{[-0.81]}\end{array}$ & $\begin{array}{c}4.24^{*} \\
{[1.60]}\end{array}$ & $\begin{array}{c}1.64 \\
{[0.55]}\end{array}$ & $\begin{array}{c}-0.21 \\
{[-0.09]}\end{array}$ & - & 0.30 & 0.05 & 0.84 \\
\hline Güney Afrika & 4.86 & $\begin{array}{c}-0.25^{* *} \\
{[-2.15]}\end{array}$ & $\begin{array}{c}-2.64 \\
{[-0.91]}\end{array}$ & $\begin{array}{c}1.24 \\
{[1.49]}\end{array}$ & $\begin{array}{c}-2.37^{* * *} \\
{[-2.64]}\end{array}$ & - & - & 0.62 & 0.51 & 0.75 \\
\hline Hindistan & 3.97 & $\begin{array}{c}-0.88^{* * *} \\
{[-3.02]}\end{array}$ & $\begin{array}{c}1.39 \\
{[1.92]^{* *}}\end{array}$ & $\begin{array}{c}2.21^{* * *} \\
{[2.48]}\end{array}$ & $\begin{array}{c}-3.77^{* * *} \\
{[-3.08]}\end{array}$ & - & - & 0.27 & 0.17 & 0.69 \\
\hline Türkiye & 1.87 & $\begin{array}{c}-1.70^{* * *} \\
{[-3.72]}\end{array}$ & $\begin{array}{c}0.41 \\
{[0.24]}\end{array}$ & $\begin{array}{c}-4.88^{*} \\
{[-1.53]}\end{array}$ & $\begin{array}{c}-3.51 \\
{[-1.11]}\end{array}$ & $\begin{array}{c}-2.37 \\
{[-0.68]}\end{array}$ & - & 0.38 & 0.27 & 0.14 \\
\hline
\end{tabular}

Not: Köşeli parantez içindeki değerler, $t$ istatistikleri olup * ${ }^{* * *}$ ve ${ }^{* * *}$ sırasıyla $\% 10, \% 5$ ve $\% 1$ anlamlılık düzeyinde katsayıların istatistikse olarak anlamlı olduğunu ifade etmektedir. Tahminlerdeki otokorelasyon ve değişen varyans sorunları, Newey-West yöntemi ile giderilmiştir. Kukla değişkenler Brezilya için K1: 1983, K2: 1987, K3: 1994, K4: 2000 ve K5: 2004; Endonezya için K1: 1989, K2: 1998, K3: 2001 ve K4: 2004 ; G. Afrika için K1: 1984, K2: 1999 ve K3: 2008 ve Türkiye için K1: 1988, K2: 2005, K3: 2008 ve K4: 2011 olarak alınmıştır. JB; Jarque-Bera normallik sınaması olasılık değeri olup, bu değer 0.05 'ten büyük olduğunda, ilgili modelin hata teriminin normal dağılıma sahip olduğu ve elde edilen test istatistiklerinin güvenilir olduğu kabul edilmektedir.

Tablo 5'teki sonuçlar incelendiğinde; yatırımtasarruf açı̆ı̆ının GSYH'ye oranındaki bir puanlık artışın, büyüme oranında sırasıyla Brezilya için 2.96, Endonezya için 0.51 , Türkiye için 1.70, Güney Afrika için 0.25 ve Hindistan için 0.88 puan azalışa yol açtığı görülmüştür. Bu durum, Kırılgan beşli ülkeleri için büyümenin azalmasında en önemli etkenlerden birinin tasarruf-yatırım açığı olduğunu ortaya koyması yönüyle dikkat çekicidir. Bu sonuçlar, teorik beklentilerle uyumlu olup, tasarruf-yatırım açığının, ülkelerin büyüme oranlarını negatif yönde etkilediği ve kırılgan beşli ülkelerinin söz konusu açığı finanse edebilmek için yurtdışı fonlara bağımlılığının artması ve bunun sonucu olarak ülkelerin dış şoklara karşı duyarlılığının artmasını destekler niteliktedir.

\subsection{Kısa Dönem Analizi: Hata Düzeltme Modeli}

Kısa dönem analizi, hata düzeltme modeli çerçevesinde, farkı alınmış seriler ve uzun dönem analizinden elde edilen hata terimi serilerinin bir dönem gecikmeli değeri (Hata Düzeltme Terimi: Error Correction Term: $E C T_{t-1}$ ) kullanılarak yine DOLS yöntemiyle gerçekleştirilmiş, elde edilen sonuçlar Tablo 6'da gösterilmiştir.

Tablo 6: Kısa Dönem Analiz Sonuçları

\begin{tabular}{|c|c|c|c|c|c|c|}
\hline Bağımlı Değişken & Sabit Terim & $E C T_{t-1}$ & $\Delta S I$ & $R^{2}$ & $\overline{\boldsymbol{R}}^{2}$ & $J B$ \\
\hline$\Delta G_{\text {Brezilya }}$ & 0.47 & $-0.95 *[-1.73]$ & $-0.74^{* * *}[-3.77]$ & 0.21 & 0.06 & 0.76 \\
\hline$\Delta G_{\text {Endonezya }}$ & 0.36 & $-0.92^{* * *}[-6.28]$ & $-0.44^{* * *}[-2.98]$ & 0.54 & 0.51 & 0.17 \\
\hline$\Delta G_{G . \text { Afrika }}$ & -0.04 & $-0.94 *[-3.65]$ & $-0.65^{* * *}[-4.20]$ & 0.51 & 0.47 & 0.48 \\
\hline$\Delta \boldsymbol{G}_{\text {Hindistan }}$ & -0.06 & $-1.14^{* * *}[-8.87]$ & $-1.15^{* * *[-4.89]}$ & 0.49 & 0.45 & 0.53 \\
\hline$\Delta G_{\text {Türkiye }}$ & -0.07 & $-0.90 * * *[-5.28]$ & $-2.07^{* * *}[7.81]$ & 0.79 & 0.78 & 0.85 \\
\hline
\end{tabular}

Not: Köşeli parantez içindeki değerler, $t$ istatistikleri olup * ve *** sırasıyla $\% 10$ ve $\% 1$ anlamlılık düzeyinde katsayıların istatistiksel olarak anlamlı olduğunu ifade etmektedir. Tahminlerdeki otokorelasyon ve değişen varyans sorunları, Newey-West yöntemi ile giderilmiştir. JB; Jarque-Bera normallik sınaması olasılık değeri olup, bu değer 0.05 'ten büyük olduğunda, ilgili modelin hata teriminin normal dağılıma sahip olduğu ve elde edilen test istatistiklerinin güvenilir olduğu kabul edilmektedir.

Tablo 6'da Kırılgan Beşli ülkeleri için tahmin edilen beş modelde hata düzeltme terimlerinin katsayılarının negatif ve istatistiksel olarak anlamlı olduğu sonucu elde edilmiştir. Uzun dönemde birlikte hareket eden seriler arasında meydana gelen dönemsel sapmalar ortadan kalkmakta ve seriler yeniden uzun dönem denge değerlerine yaklaşmaktadır. Bu durum, yapılan uzun dönem analizlerinin doğru sonuç verdiğini de bir kanıt oluşturmaktadır. Tasarruf-yatırım açığının kısa dönemde de büyüme oranlarını azaltıcı etkisinin 
olduğu ve bu etkilerinin istatistiksel olarak anlamlı olduğu görülmüştür.

\section{SONUÇ ve ÖNERILER}

İstikrarlı ve güçlü bir ekonomik büyüme, bütün ülkenin temel hedeflerinden biridir. Bu nedenle ekonomik büyümenin ülkelerin finansal yapıları, küresel ekonomiyle entegrasyonları, iç ve dış talep yapıları, ulusal tasarruf ve yatırımlarıyla olan ilişkileri ekonomi literatüründe sıklıkla tartışılmıştır. Bu çalışmada; kırılgan beşli olarak adlandırılan Brezilya, Endonezya, Hindistan, Güney Afrika ve Türkiye'de tasarruf-yatırım açı̆̆ı ile ekonomik büyüme arasındaki ilişkiler ekonometrik olarak analiz edilmiştir. Bu ülkelerin temel ortak özellikleri; tasarruf açı̆̆ı veriyor olmaları ve büyüme için dışa bağımlııklarıdır. Yapılan ekonometrik analizler sonucunda; ülkelerin tasarruf açıkları ile büyümeleri arasında negatif yönlü bir ilişki tespit edilmiştir. Yani bu ülkelerin tasarruf açığının artması, büyüme oranlarının azalmasına sebep olmaktadır. Elde edilen bu bulgular literatürdeki; Solow (1956), Cass (1965), Koopmans (1965), Romer (1986), Bacha (1990), De Gregorio (1992), Jappelli ve Pagano (1994), Deaton ve Paxson (2000) ve Van vd. (2014) çalışmalarıyla uyumludur.

$\mathrm{Bu}$ çalışmada elde edilen bulgulara dayanarak; söz konusu ülkelerin sürdürebilir ve istikrarlı bir büyüme performansı sergileyebilmeleri ve dış şoklara karşı dayanıklılıklarını arttırabilmeleri için, ulusal tasarruf oranlarının yükseltilmesine yönelik yapısal reformlara öncelik vermelerinin gerektiği söylenebilir. Bu bağlamda söz konusu ülkelerin mali piyasalarını, yurtiçi tasarrufları özendirecek şekilde organize etmesi ve portföy olanaklarını attırmasının yararlı olacağı düşünülmektedir.
Güney Afrika, Brezilya, Endonezya ve Hindistan'da gelir dağıımı eşitsizliğinin ortadan kaldırılması ve kişibaşına düşen milli gelirin arttırılması, bireylerin yaşam standartlarını yükselterek, daha fazla tasarruf yapabilir hale gelmelerine katkı sağlayacaktır. Söz konusu ülkelerin döviz kurlarının oldukça dalgalı bir seyir izlediği gözlemlenmiş olup, bu konuda da istikrarı sağlayıcı tedbirlerin alınması yerinde olacaktır. Türkiye, Brezilya ve Güney Afrika'nın 2010'dan itibaren ekonomik büyüme oranlarının düşmeye başladığı, politika yapıcıların ülkelerinde ekonomik büyümeyi arttırıcı önlemleri almalarının gerektiği söylenebilir. Analize konu edilen beş ülkede de net sermaye girişlerinin ülkelerin ekonomik büyümesini yeterince destekleyici düzeyde olmadığı görülmüş olup, ekonomi yönetimlerinin portföy yatırımlarını ve doğrudan yabancı yatıımları arttırıcı düzenlemelere öncelik vermeleri gerekmektedir.

Türkiye özelinde ise; son on yılda artan iç talep ve aktif inşaat sektörüne dayalı bir ekonomik büyüme yaşanmıştır. Söz konusu büyümenin finansmanı hususunda ise dışa bağımlılık giderek artmıştır. Türkiye, 2014 yılında verdiği \%7 oranındaki tasarrufyatırım açığı ile kırılgan beşli arasında en kırılgan ülke pozisyonundadır. Döviz kuru, enflasyon, işsizlik ve büyüme rakamları topluca göz önünde bulundurulduğuna da aynı durum görülmektedir. Bu sebeple Türkiye'de diğer ülkelere göre daha hızlı önlemler alınması, ekonomik ve hukuki reformların yanı sıra, katma değeri yüksek ürünler üretmeye yönelik çalışmaların yoğunlaştııılması giderek önemli bir hal almaktadır. Ekonominin verdiği olumsuz sinyallar doğru algılanmalı, ekonomik ve siyasi istikrarın korunmasına özen gösterilmelidir.

\section{SON NOTLAR}

*Bu çalışma, 7-9 Mayıs 2015 tarihlerinde Edirne'de düzenlenen 16. Uluslararası Ekonometri, Yöneylem Araştırması ve İstatistik Sempozyumu'nda aynı başlıkla sunulan ve özeti basılan bildirinin, yeniden düzeltilmiş ve büyük ölçüde geliştirilmiş şeklidir.

\section{KAYNAKLAR}

Aghion, P. ve Howitt, P (1992) "A Model of Growth Through Creative Destruction" Econometrica, 60(2): 323-351.

Ahmed, S. ve Zlate, A. (2014) "Capital Flows to Emerging Market Economies: A Brave New World?" Journal of International Money and Finance, 48, 221248.
Aizenman, J., Binici, M. ve Hutchison, M. M. (2014) "The Transmission of Federal Reserve Tapering News to Emerging Financial Markets" National Bureau of Economic Research (No. w19980).

Bacha, E. L. (1990) "A Three-Gap Model of Foreign Transfers and The GDP Growth Rate in Developing 
Countries" Journal of Development economics, 32(2): 279-296.

Bai, J. ve Perron, P. (1998) "Estimating and Testing Linear Models with Multiple Structural Changes" Econometrica, 66(1): 47-78.

Banerjee, A., Lumsdaine, R. L. ve Stock, J. H. (1992) "Recursive and Sequential Tests of The Unit Root and Trend Break Hypotheses: Theory and International Evidence" Journal of Business and Economic Statistics 10: 271-288.

Bernanke, B. S. (2005) "The Global Saving Glut and the U.S. Current Account Deficit" Homer Jones Lecture, St. Louis, Missouri, April 2005. http://www.federalreserve. gov/boarddocs/speeches/2005/20050414/default. $\underline{\mathrm{htm}}$

Buiter, W. H. (1981)“Time Preference and International Lending and Borrowing in an OverlappingGenerations Model" Journal of Political Economy, 89: 769-797.

Cass, D. (1965) "Optimum Growth in an Aggregative Model of Capital Accumulation"The Review of economic studies: 233-240.

CEBR (2014). World Economic League Table 2015 Highlights, December 26,2014. http://www.cebr. com/reports/world-economic-league-table-2015/.

Cheung, C., Furceri, D. ve Rusticelli, E. (2013)“Structural and Cyclical Factors Behind Current Account Balances" Review of International Economics, 21(5): 923-944.

Cullison, W. E. (1993) "Saving Measures as Economic Growth Indicators" Contemporary Economic Policy, 11 (1): 1-8.

Deaton, A. ve Paxson, C. (2000) "Growth and Saving among Individuals and Households" Review of Economics and Statistics, 82(2): 212-225.

De Gregorio, J. (1992) "Economic Growth in Latin America" Journal of development economics, 39(1): 59-84.

Eğilmez, M. (2013) "Kırılgan Beşli", http://www. mahfiegilmez.com/2013/11/krlgan-besli.html (05.04.2015)

Feyrer, J. ve Shambaugh, J. (2012) "Global Savings and Global Investment: The Transmission of Identified Fiscal Shocks" American Economic Journal: Economic Policy, American Economic Association, 4(2): 95-114.

Gallagher, K. (2012) "The Myth of Financial Protectionism: The New (and Old) Economics Of Capital Controls" Political Economy Research Institute Working Paper, 278.
Gente, K., León-Ledesma, M. A. ve Nourry, C. (2014) "External Constraints and Endogenous Growth: Why Didn't Some Countries Benefit From Capital Flows?" Journal of International Money and Finance, 10.

Granger, C.W.J. (1969) “Investigating Causal Relations by Econometric Models and Cross-Spectral Methods" Econometrica, 37(3): 424-438.

Howitt, P. ve Aghion, P. (1998) "Capital Accumulation and Innovation as Complementary Factors in LongRun Growth" Journal of Economic Growth, 3(2): 111130.

IMF (2012) "The Liberalization and Management of Capital Flows: An Institutional View" November 2012.

Insel, A. ve Sungur, N. (2003) "Sermaye Akımlarının Temel Makroekonomik Göstergeler Üzerindeki Etkileri: Türkiye Örneği1989-: III1999-: IV" Turkish Economic Association, Discussion Paper, (No. 2003/8).

Jappelli, T. ve Pagano, M. (1994) "Saving, Growth, and Liquidity Constraints" The Quarterly Journal of Economics: 83-109.

Kalkınma Bakanlığı, (2012) "Yüksek Büyümenin Sürdürülebilirliği: Yurtiçi Tasarrufların Rolü Türkiye Ülke Ekonomik Raporu", Dünya Bankası'nın aynı başlıklı raporundan çeviri, http:// siteresources.worldbank.org/turkeyinturkishextn/ Resources/455687-1331626580764/cem yurticitasarruflar_tammetin.pdf, (17.06.2015).

Kapetanios, G. (2005) "Unit-Root Testing Against the Alternative Hypothesis of Up to M Structural Breaks" Journal of Time Series Analysis, 26(1): 123-133.

Kaya, V., Yılmaz, Ö. ve Talaş, E. (2009) "Yükselen Piyasa Ekonomileri ve Türkiye,1990-2006: Neredeyiz?Emerging Market Economies and Turkey, 1990-2006: Where are we?" Atatürk Üniversitesi Sosyal Bilimler Enstitüsü Dergisi, 13(1): 315-342.

Koopmans, T.C. (1965) "On the Concept of Optimal Economic Growth" In The Econometric Approach to Development Planning, Amsterdam: North-Holland.

Kynge, J. (2014) "EM's "Fragile Five" Back Under Pressure" Financial Times, 28 August,2014.http://www. ft.com/intl/cms/s/0/7dc3688c-2ea6-1 1 e4-bffa-00144 feabdc0.html\#axzz3WnxP2ak3 (09.04.2015).

Landon, T. J. (2014) "Fragile Five is the Latest Club of Emerging Nations in Turmoil" New York Times. http://www.nytimes.com/2014/01/29/business/ international/fragile-five-is-the-latest-club-ofemerging-nations-in-turmoil (07.04.2015).

Lane, P.R. ve Pels, B. (2012) "Current Account Imblances in Europe" IIIS Discussion Paper No.397/April 2012 
Lee, J. ve Strazicich, M.C. (2003) "Minimum Lagrange Multiplier Unit Root Test with Two Structural Breaks" The Review of Economics and Statistics, 85(4): 10821089

Looney, R. E. (1996) "National Savings In Pakistan: Causal Linkages with The Macroeconomy" Savings and Development,20: 461-475.

Lumsdaine, R. L. and Papell, D. H. (1997). Multiple trend breaks and the unit root hypothesis. Review of Economics and Statistics, 79(2), 212-217.

Maki, D. (2012) "Tests for Cointegration Allowing for an Unknown Number Of Breaks" Economic Modelling, 29(5): 2011-2015.

Mercan, M. ve Göçer, İ. (2012) "Zamanlararası Dış Denge Ve Optimizasyon Yaklaşımları Çerçevesinde Türkiye'de Cari Açığın Sürdürülebilirliği" Akdeniz Universitesi Iktisadi ve Idari Bilimler Fakültesi Dergisi, 12(24): 73-101.

Mohan, R. (2008) "Growth Record of the Indian Economy, 1950-2008: A Story Of Sustained Savings and Investment" Economic and Political Weekly: 61-71.

Morgan Stanley (2013) "FX Pulse Preparing for Volatility" Global Outlook, 01.08.2013 http://www. morganstanleyfa.com/public/projectfiles/dce4d16815f9-4245-9605-e37e2caf114c.pdf (05.02.2015)

Ng, S. ve Perron, P.. (2001). Lag Length Selection and The Construction of Unit Root Tests With Good Size and Power. Econometrica, 69: 1519-1554.

Obstfeld, M. (1982a) “Transitory Terms of Trade Shocks and The Current Account: The Case of Constant Time Preference" National Bureau of Economic Research Working Paper Series,(No: 834).

Obstfeld, M. (1982b) "Aggregate Spending and the Terms of Trade: Is There a Laursen-Metzler Effect?" Quarterly Journal of Economics 97: 251-270.

Obstfeld, M. (2012) "Financial Flows, Financial Crises, and Global Imbalances" Journal of International Money and Finance, 31(3): 469-480.

OECD (2013) http://www.oecd.org/eco/surveys/ Brazil_2013_Overview_ENG.pdf

Örnek, İ. (2008) "Yabancı Sermaye Akımlarının Yurtiçi Tasarruf ve Ekonomik Büyüme Üzerine Etkisi: Türkiye Örneği" Ankara Üniversitesi SBF Dergisi,63(02): 199207.

Öz, S. (2007) "Küresel Rekabette Yeni Bir Güç: Hindistan" TUSIAD-Sabancı Üniversitesi Rekabet Forumu, Kasım,2007.
Prasad, E. S., Rajan, R. G. ve Subramanian, A. (2007) "Foreign Capital and Economic Growth" National Bureau of Economic Research (No. w13619).

Perron, P. (1989) "The Great Crash, The Oil Price Shock, and The Unit Root Hypothesis" Econometrica: Journal of the Econometric Society,57(6): 1361-1401

Perron, P. (1997) "Further Evidence on Breaking Trend Functions in Macroeconomic Variables" Journal of Econometric, 80: 355-385.

Romer, P. M. (1986) “Increasing Returns and Long-Run Growth" The Journal of Political Economy,94(5): 10021037.

Romer, P.M. (1990) "Endogenous Technological Change" Journal of Political Economy, 98(5): 71-102.

Sachs, J. (1981) "The Current Account and Macroeconomic Adjustment in The 1970s" Brookings Papers on Economic Activity, 1: 201-282.

Saikonen, P. (1991) "Asymptotic Efficient Estimation of Cointegration Regressions" Economteric Theory, 7: 1-21.

Solow, R. (1956) "A Contribution to The Theory of Economic Growth" Quarterly Journal of Economics, 70(1): 65-94.

Stakénas, P. (2010) “Dynamic OLS Estimation of Fractionally Cointegrated Regressions", Amsterdam School of Economics, Discussion Paper, No: 11.

Steiner, A. (2013) "The Accumulation of Foreign Exchange by Central Banks: Fear of Capital Mobility?" Journal of Macroeconomics, 38: 409-427.

Stock, J. H. ve Watson, M.W. (1993) “A Simple Estimator of Cointegrating Vectors in Higher Order Integrated Systems" Econometrica: Journal of the Econometric Society, 61(4): 783-820.

Svensson, L. E. ve Razin, A. (1983) “The Terms of Trade and The Current Account: The Harberger-LaursenMetzler Effect" The Journal of Political Economy, 91(1): 97-125.

Tang, C.F. ve Chua, S.Y.(2012) "The savings-growth nexus for the Malaysian economy: a view through rolling sub-samples" Applied Economics,44(32): 41734185.

Toda, H. Y. Ve Yamamoto, T. (1995). "Statistical Inference in Vector Autoregressions with Possibly Integrated Processes" Journal of Econometrics, 66(1): 225-250.

Van, C. L., Nguyen, T. A. ve Tuan, T. D. (2014) "Saving Rate, Total Factor Productivity and Growth Process for 
Developing Countries" Department of Research, (No. 2014-424), Ipag Business School.

Yeldan, E. (2009)“Kapitalizmin Yeniden Finansallaşması ve 2007/2008 Krizi:Türkiye Krizin Neresinde?" Çalışma ve Toplum, 1: 11-28.

Yılancı, V. ve Özcan, B. (2010) "Yapısal Kırılmalar Altında Türkiye için Savunma Harcamaları ile GSMH Arasındaki İlişkinin Analizi" C.Ü. İktisadi ve Idari Bilimler Dergisi, 11(1): 21-33.
Zivot, A. ve Andrews, D.W.K. (1992) “Further Evidence on The Great Crash The Oil Price Shock and The Unit Root Hypothesis" Journal of Business and Economic Statistics 10(3): 270-251. 